\title{
THE IMPACT OF SELECTED PROCESSES AND TECHNOLOGICAL PARAMETERS ON THE GEOMETRY OF THE WELD POOL WHEN WELDING IN SHIELD GAS ATMOSPHERE
}

\author{
Josef BradáČ**, Jaromír MoraveC \\ Department of Engineering Technology, Faculty of Engineering, Technical University of Liberec. Studentská \\ 1402/2, 46117, Czech Republic \\ * corresponding author: josef.bradac@tul.cz
}

\begin{abstract}
This paper is focused on welding with a consumable electrode in a gas shield atmosphere and its main aim is to show the influence of selected processes and technological parameters on the geometry of the weld pool in terms of theoretical and experimental views. For this purpose, the parametric areas defined by the change of the welding current and welding rate were determined. Apart from the influence of these parametric areas, the influence of other technological input variables, including the wire diameter and preheating temperature, was also studied. The experimentally obtained geometric data of the weld pool can be used for technological welding procedures WPS and especially for simulation calculations to obtain a more accurate numerical model of the heat source. This makes it possible to get accurate simulation results and to better understand the impact of other variables that influence the welding process. This all helps to the optimization of the welding process for several applications.
\end{abstract}

KEYWORDS: weld pool geometry; process and technological parameters; GMAW; numerical simulations.

\section{INTRODUCTION}

To understand any action, it is first necessary to obtain a mathematical description of this action. The more detailed and precise description, the better the possibility to determine its behaviour and predict subsequent action. When predicting the response of the particular process to a various external impulse, it is necessary to establish a mathematical sequence of conditions, which, on the base of specified input variables, determine the particular accuracy of the result. The accuracy of the simulation-based processes depends mainly on the amount and accuracy of the input variables. The higher the quantity and quality of input variables, the greater the probability to obtain results that reflect the real state.

The welding process can be characterized as a mathematical problem with many variables, but with only one unknown, which is the shape of the weld pool. It is possible, based on experience, with a certain degree of probability, to predict the shape, but the result must then be confirmed experimentally. The biggest pitfall in predicting the weld pool shape is the great interdependence of variables that affect the final geometry of the weld.

The principle of fusion welding is intense local heating, the associated melting of the base material and subsequent crystallization of the weld pool. The shape and dimensions of the weld pool is given by the shape of the temperature gradient and the intensity of the heat transfer to the surrounding material, depending on its thickness and the material properties.

The knowledge of the shape of the weld pool is very important both in terms of design and technology. The experiments and their results presented in this paper were realized primarily to achieve more accurate results of simulation calculations. Because, when defining the respective model of the heat source, it is necessary to consider not only the influence of process parameters, but also the influence of technological parameters and physical-chemical processes. The main problems are mainly the description of thermal fields based on the shape of the temperature gradient, the heat transfer efficiency, the type of the protective atmosphere, preheating, reheating and interpass temperatures, but also the chemical composition, the effect of surface active components and heat transfer type in the weld pool (conduction, convection, radiation).

Although it is not possible to solve the fusion welding technology complex, there are approaches allowing to solve certain parts of this process. Besides classic calculations of the temperature, stress and strain fields, the effect of surface active elements, such as sulphur and oxygen, and their influence on the melting depth or the flow direction in the welding bath can be 1-3. Processes related to the heat transfer in the weld pool 4, or the material melting efficiency are simulated [5, 6]. It is also possible to describe the influence of the metal transmission type on the geometry of the weld pool, or the effect of the droplet size on the heat diffusion in the weld pool [7]. Other studies deal with a more accurate prediction of the chemical composition of the welded metal. These include the determination of the loss of alloying elements by their burn out [8, 9] based on Langmuir equation of the pressure gradient, which controls the mass transfer. It is also possible to simulate the intensity of the solubility of the gas during arc welding, calculated according to Sievert law [10. It can also 
simulate the phase transformations of steels using the Johnson-Mehl-Avrami-Kolmogorov equation [11, or microstructure $\mathrm{C}-\mathrm{Mg}$ and HSLA steel using the Scheile additive rule [12]. Research is also focused on the modelling of the grain growth in the HAZ using the Monte Carlo method [13] and modelling the properties of the inclusions during precipitation and subsequent diffusion processes.

\section{THE EFFECT OF PROCESS PARAMETERS ON THE WELD POOL GEOMETRY}

Arc fusion welding is characterized by a great number of variables, which influence the final geometry of the weld pool. These input parameters can be divided into three basic groups - the process input parameters, technological input parameters and physical-chemical parameters.

The largest group of input parameters is represented by process parameters. These parameters are set up directly before welding and can be corrected during welding. They are highly dependent on the design of the power source and its static and dynamic characteristics. The most important process parameters include the welding current (current density), welding voltage and welding speed. Increasing the welding speed with the proportional increase of its intensity creates the portion of heat utilized for melting the base material. Simultaneously, the temperature gradient is increased and isotherms are closer to the heat source in all directions, mostly before the source. The maximal temperature in the melting zone increases, see Figure 1] [14]. The increasing temperature also increases the melting efficiency irrespective of the heat source type.

On the basis of the main process parameters, the most important variable used during welding can be determined - the input heat. The specific input heat Qv determines the heat input per weld length unit and is given by the existence of the weld pool and the overall heat balance of the weld with respect to the input and output heat, transmission losses and arc protection. The values of the specific heat input allow to predict the range of the thermal effects, stress, and strain fields after welding. The determined value also specifies the limits for the welding of individual materials. The specific heat input can be calculated by this formula:

$$
Q_{v}=\eta_{0} \frac{U I}{v_{s}}
$$

The process parameters are not the sole parameters influencing the shape and dimensions of the weld pool. There are also other parameters, including primarily the wire feed speed, current density, polarity at the electrode, the wire extension, torch slope, shielding gas flow, the shape and dimensions of the weld surface, the metal transfer, and the welding position.
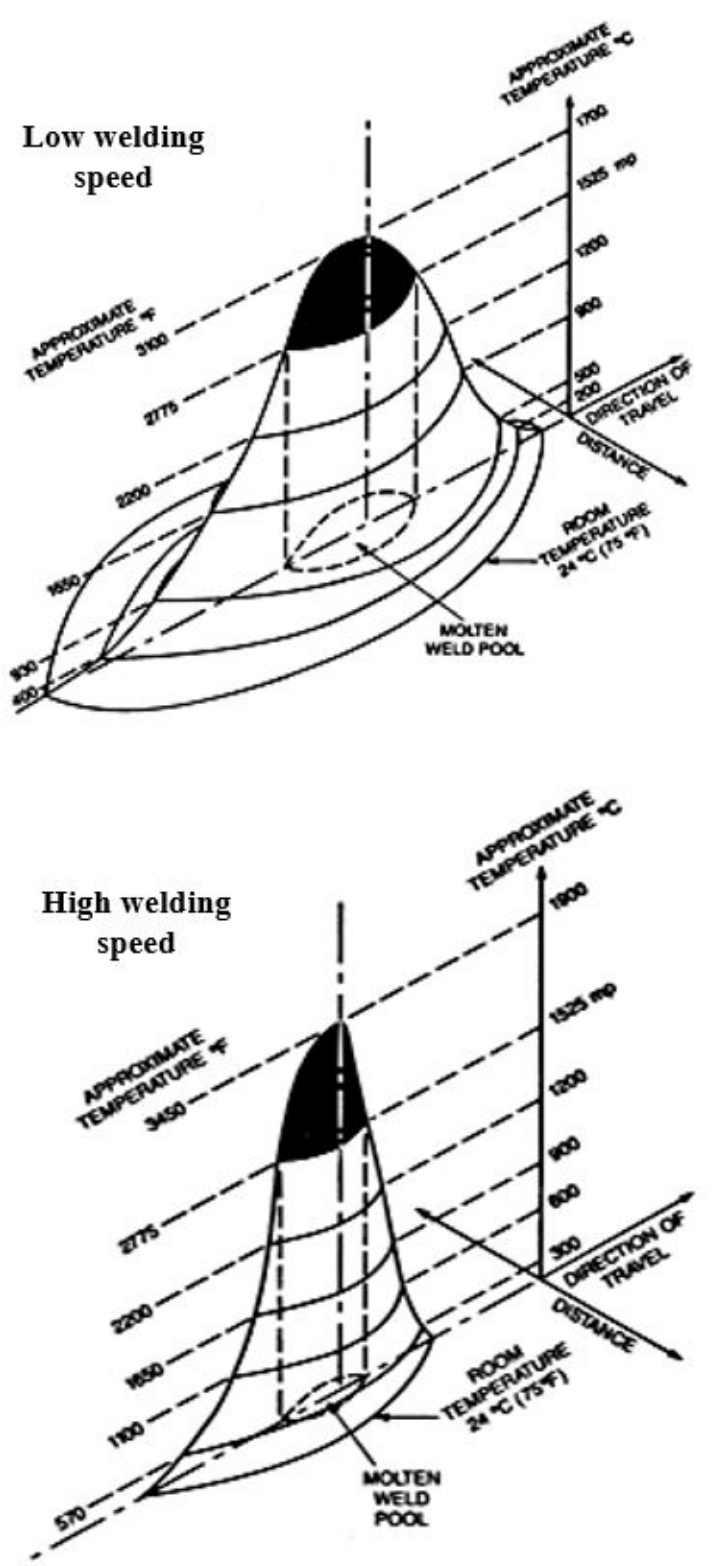

Figure 1. Thermal conditions in the weld pool for different welding speeds [14].

\section{THE EFFECT OF TECHNOLOGICAL PARAMETERS}

Technological input parameters are the second largest group of input variables. These parameters are typically determined by the base material, structural design of the welded joint and the operating conditions of the final product. The most commonly used technological input parameters include the wire type and diameter (consumable electrode), the type and amount of shielding gas, the shape and geometry of the welded surfaces (weld type), the preheating temperature, reheating, interpass temperature or subsequent heat treatment of the weldment.

Technological input parameters greatly affect the value and set-up of process parameters. This means that they considerably influence the resulting geometry of the weld pool. 


\subsection{THE EFFECT OF WIRE DIAMETER}

Generally, the larger wire diameter requires a higher welding current to melt. Using smaller wire diameter for the same value of the welding current increases the current density and the coefficient of melting is greater. Small diameter wires enable larger number of droplets transmitted in the arc, both for the short and the long electric arc. This means positive effect in case of multilayer and root welds because, due to the increased number of drops, a greater surface smoothness can be achieved. The current density can then be applied. The selection of the wire diameter is based on the material thickness, the joint type and welding position.

In the engineering practice, in the case of GMAW welding method, the following wire diameters are used: $0.6,0.8,1.0,1.2,1.4$ and $1.6 \mathrm{~mm}$. Selection of the suitable wire diameter depends, besides the already mentioned rules, on the final product and its dimensions. The level of work load and the surrounding conditions are also important. When welding steel structures, the most frequent wire diameters are 0.8 , 1.0 and $1.2 \mathrm{~mm}$. The increasing wire diameter decreases the current density. In the case of using the same values of welding current and changing the wire diameter from 0.8 to $1.0 \mathrm{~mm}$, the resulting decrease of the current density is $36 \%$ and when changing the diameter to $1.2 \mathrm{~mm}$ the decrease in the current density is another $20 \%$ [15].

\subsection{THE EFFECT OF PREHEATING AND INTERPASS TEMPERATURE}

By using preheating during welding, it is possible to improve the quality of the welded joint. Its application leads to the reduction of the cooling rate, and thereby reduction or elimination of the formation of selected structural phases, or reduction of the level of internal stresses. The preheating temperature depends primarily on the chemical composition of the welding material and the initial and final values of the selected transformation temperature. It must be high enough to achieve the desired structural phase. Also, it should not be too high to prevent excessive grain coarsening in the HAZ.

The preheating temperature is determined either computationally (low alloyed steels), or experimentally in the case of middle and high alloy steels. Experimental tests are based either on the metallographic evaluation and hardness measurement in the HAZ (possible test of impact strength), or on the cracking tests, that means tests like Tekken, the CTS, implants, etc. [16]. The main disadvantage of cracking tests is that they are highly time-consuming and usually involve high costs.

Currently used computational algorithms are based on real experiments, but they are designed primarily for standard or low-alloyed steel. The computational algorithms, like computations according to Seferian

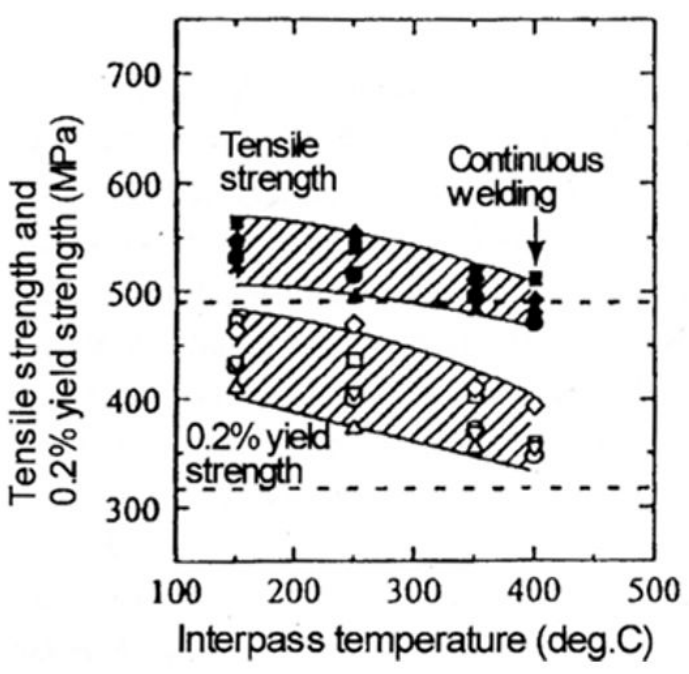

Figure 2. Mechanical properties vs. interpass temperature 17.

and Ito-Bessy, are commonly used [16. For determining the preheating temperature for each group of steels, the EN 1011 standard, which provides recommendations on welding metallic materials and describes methods for determining the preheating temperature for each specific steel group, can be used.

During welding, the multilayer weld is also important to monitor the interpass temperature. If this temperature is not monitored, there is a high probability that the mechanical properties of the welded material are affected, and the heterogeneity of material properties across the welded metal can also be expected. Using high interpass temperature for carbon ferritic steels results in a decrease in yield and ultimate strength and could cause cracking, see Figure 2 .

\section{EXPERIMENTS}

The main aim of the experimental part was to determine the effect of change in the wire diameter and preheating temperature on the geometry of the weld pool for the fillet weld type and the GMAW welding. Experiments were carried out for the parametric area corresponding to the range of the welding current from 140 to $280 \mathrm{~A}$ and the welding speed in the range $0.2-0.7 \mathrm{~m} / \mathrm{min}$. The samples were welded in a synergic mode. The obtained geometric data were then used in numerical simulations of welding to optimize a double ellipsoidal model of the heat source. Double ellipsoidal heat source model enables simulations with very good agreement with the reality, especially when simulating the electric arc welding processes.

The cold-rolled sheets of thickness $s=5 \mathrm{~mm}$ were used as the base material. Sheet material was made of low carbon steel S355J2. Experimentally determined chemical composition and mechanical properties of 

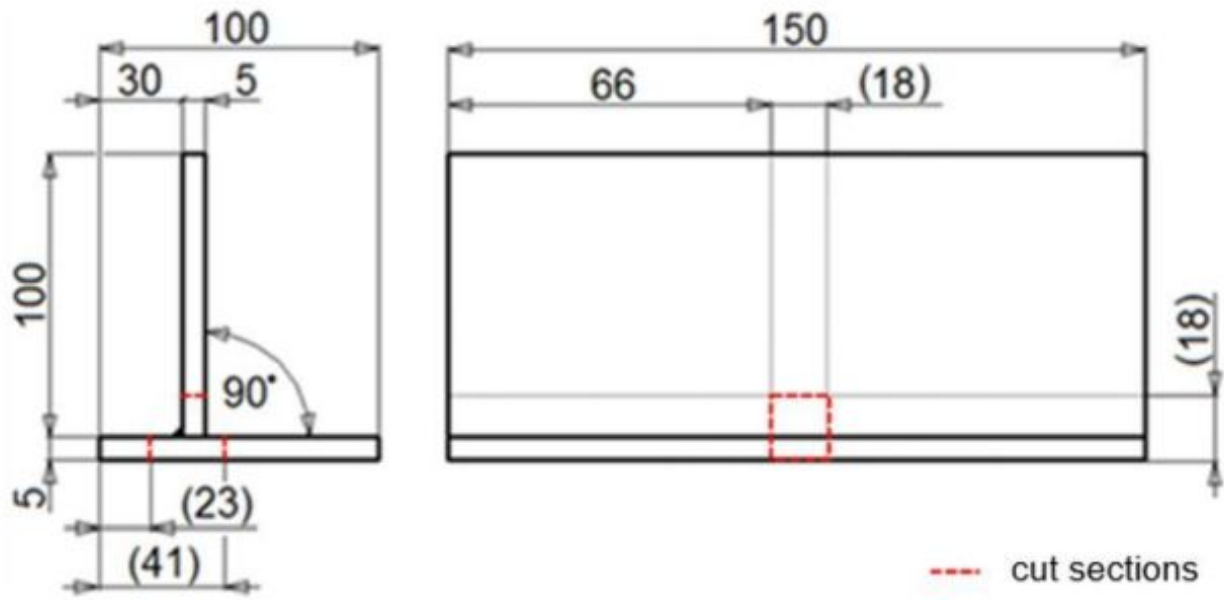

FiguRE 3. Welded parts geometry with marked cut sections.

\begin{tabular}{ccccc}
\hline $\mathrm{C}$ & $\mathrm{Si}$ & $\mathrm{Mn}$ & $\mathrm{Cr}$ & $\mathrm{P}$ \\
\hline 0.113 & 0.014 & 1.42 & 0.046 & 0.026 \\
\hline $\mathrm{Cu}$ & $\mathrm{Al}$ & $\mathrm{W}$ & $\mathrm{Nb}$ & $\mathrm{N}$ \\
\hline 0.057 & 0.063 & 0.017 & 0.024 & 0.014 \\
\hline
\end{tabular}

TABle 1. Chemical composition of steel S355J2 [\%].

\begin{tabular}{cccc}
\hline$R_{p 0.2}[\mathrm{Mpa}]$ & $R_{m}[\mathrm{Mpa}]$ & $A_{g}[\%]$ & $A_{50}[\%]$ \\
\hline 567.58 & 633.28 & 11.95 & 48.59 \\
\hline
\end{tabular}

TABLE 2. Mechanical properties of steel S355J2.

this material are shown in Tables 1 and 2 The results were calculated as an average of three individual measurements.

Figure 3 shows the assembling of the fillet weld which was used for the experiments. The weld was assembled from sheets of the following dimensions: $150 \times 100 \times 5 \mathrm{~mm}$. The sheets were milled to achieve a constant contact surface with a zero weld gap. Stitching was used before the welding process to guarantee the prescribed geometry and perpendicularity of sheets. Samples were then welded by the GMAW welding method.

Samples were welded using the power source Migatronic BDH 550 Puls Syn interconnected with the linear machine with adjustable speed. The vertical position PA and special jig were used, as shown in Figure 4 The welding jig enables to achieve the desired geometric position of welded sheets and the right definition of the heat transfer coefficient to the environment. The jig can be adjusted for the welding fillet and butt welds in different positions. Figure 4 shows a detail of welded sheets, including a schematic indication of the position of the torch to the welding sample.
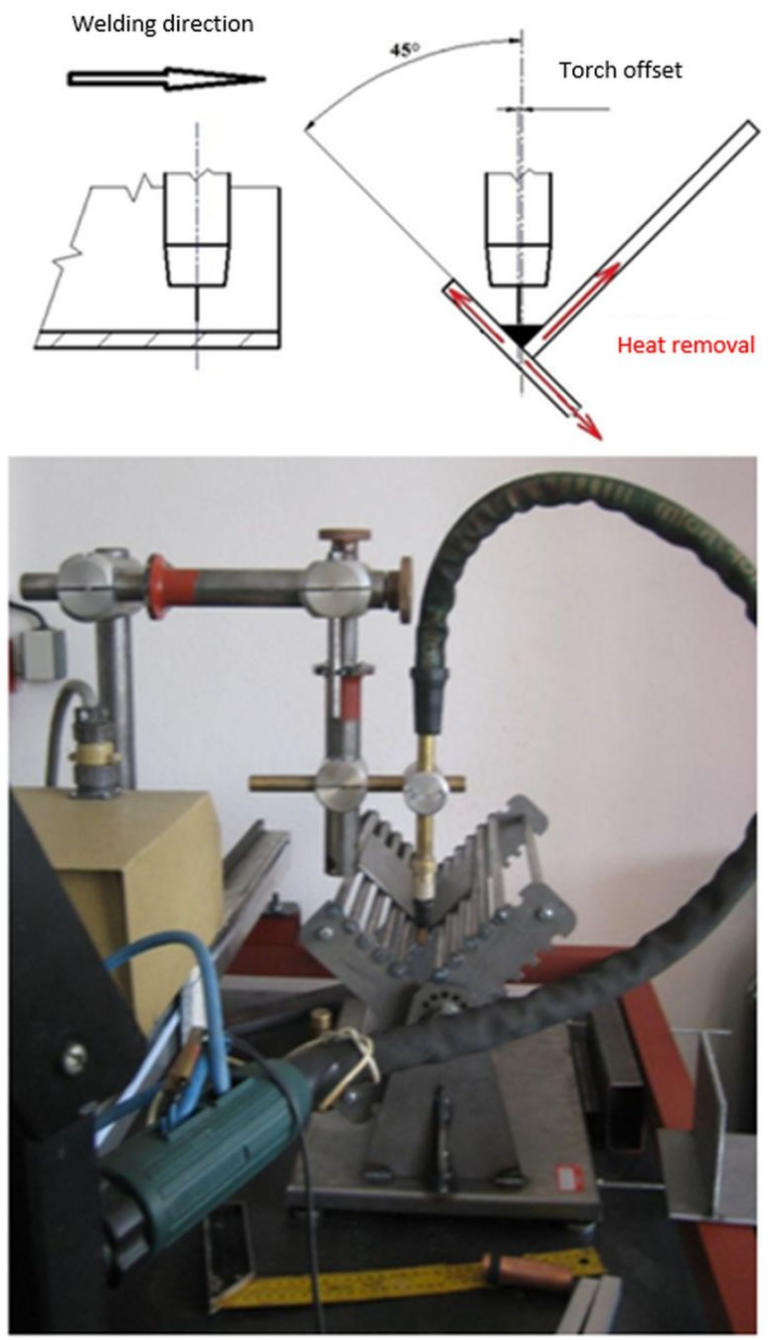

FIGURE 4. Welding position and welding equipment. 


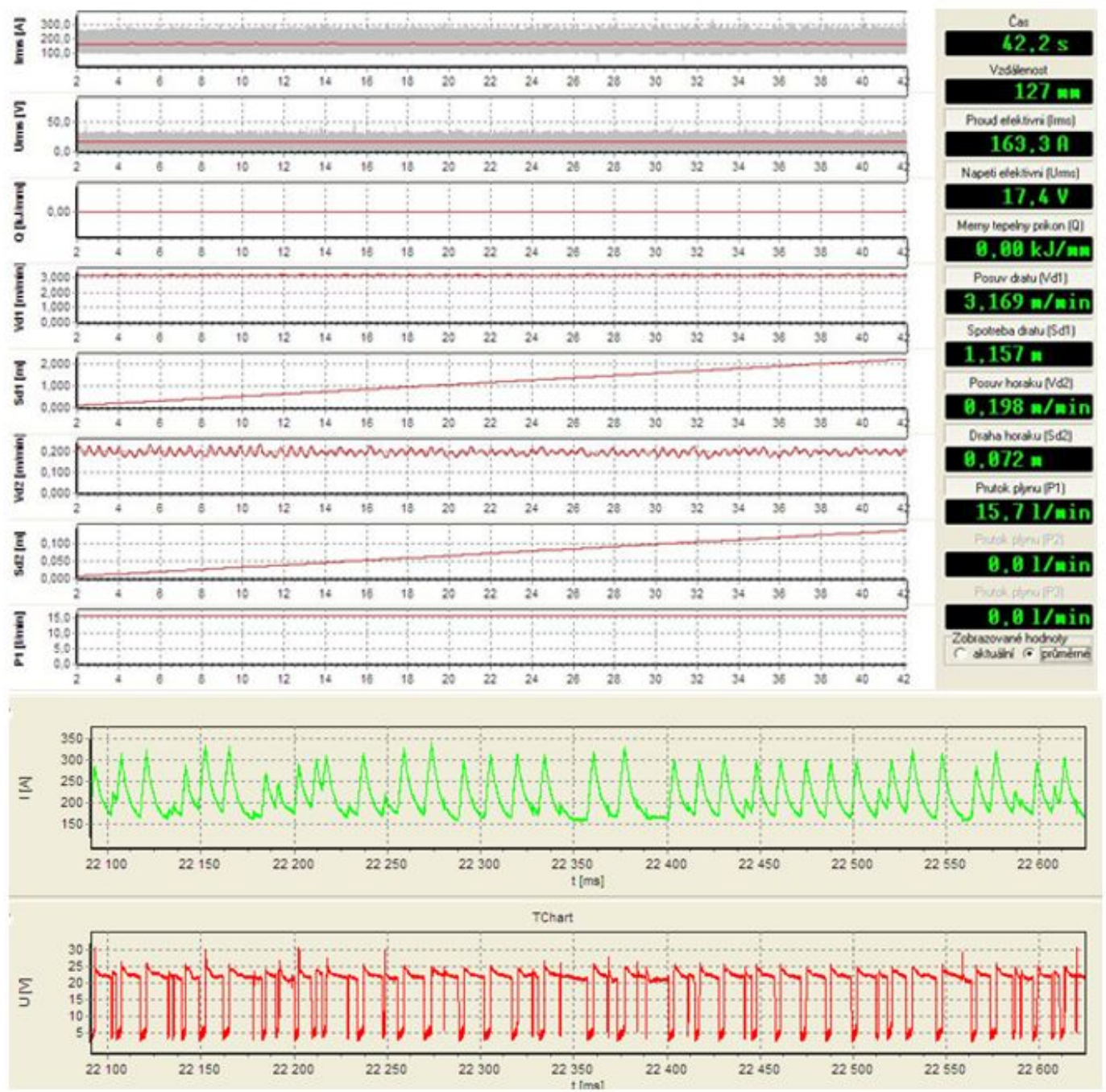

Figure 5. Example of the data control in WeldMonitor programe.

The shield gas M21 according to ISO 14175 $\left(82 \% \mathrm{Ar}, 18 \% \mathrm{CO}_{2}\right)$ was used for experiments. During welding, the basic process parameters were monitored by measuring the device and WeldMonitor 3.5 software. WeldMonitor is designed for detailed monitoring and documentation of the welding process with a high recording frequency, which exceeds $20 \mathrm{kHz}$. WeldMonitor system consists of hardware and software equipment.

WeldMonitor hardware system, which comprises sensors monitoring various parameters of the welding process, can be connected to any welding equipment. The whole system is interconnected with the host computer and makes it possible to monitor automated welding processes and the final weld quality. In the basic mode, the welding current and voltage can be monitored. The system enables real time measurement of the actual and the effective value with high precision results. In addition to these variables, it is possible to monitor the welding speed, wire feeding rate, gas flow rate, specific heat input, wire consumption, and the method of the metal transfer [18.

By using WeldMonitor, it is possible to display the results both in the text and in the graphical form. Figure 5 shows an example of recording the basic welding parameters, including the detail, which shows the welding current and voltage in case of a short circuit metal transfer. All records of measured values can be archived and possibly presented in a graphical form or in the form of data files.

All welds prepared by different process parameters were subjected to the dimensional analysis. Geometric evaluation was based on the cross section analysis of the weld using a scratch pattern. Sixteen different geometric parameters were measured, see Figure 6

Most important variable is the size of the fillet weld $a$, which is a basic calculation parameter in the design of steel structures. Furthermore, the parameters $w$ and $v_{\max }$ are also important. They define the width of the weld and the maximum penetration depth. These values can also be used in strength calculations of welded joints, but primarily in defining the mathematical description of the double ellipsoidal model of the heat source. Other parameters were determined for the classification of the weld into groups in accordance with the EN ISO 5817 standard. 


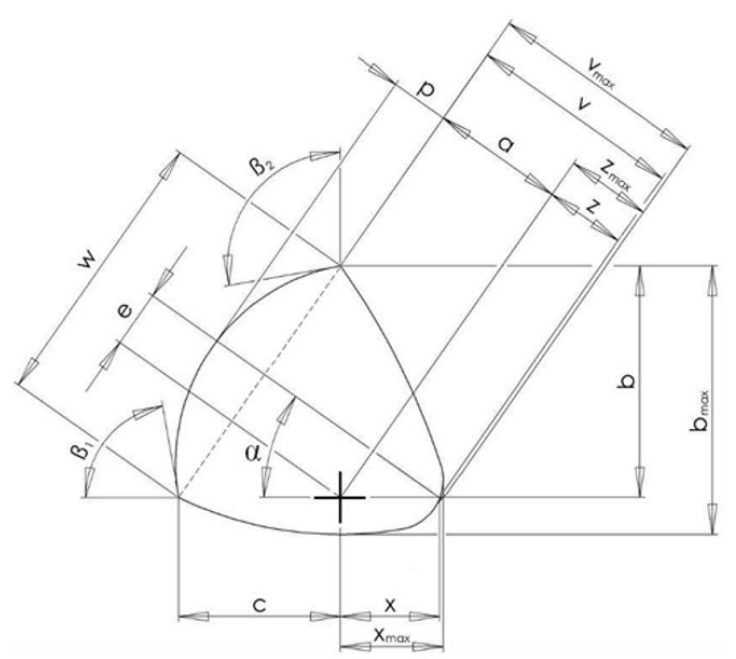

Figure 6. Schematic view of fillet weld basic geometrical parameters.
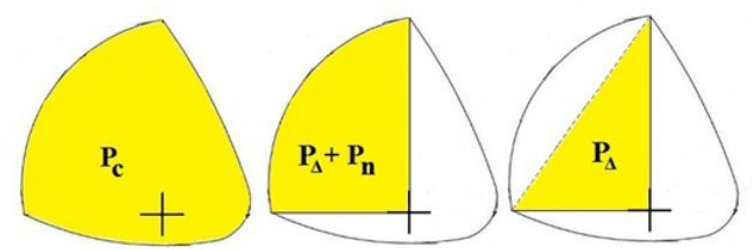

Figure 7. Schematic view of individual weld surfaces: $P_{c}$ - total weld surface, $P_{\Delta}+P_{n}$ - filler and reinforcement surface, $P_{\Delta}$ - filler material surface.

The total weld surface $P_{c}$, filler material surface $P_{\Delta}$, reinforcement surface $P_{n}$ were measured (Figure 7). The reason was to obtain more information about the mixing intensity of the base and filler material. For defining the double ellipsoidal model, it is important to know the length of each of the ellipsoids represented by $L_{c}$ and $L_{d}$ parameters. Figure 8 shows these geometrical parameters.

In total, 21 parameters were measured for each weld. All parameters were determined using the NISElements AR with an accuracy of two decimals.

\subsection{EXPERIMENTS BY DIFFERENT WIRE DIAMETER}

The wire OK Autrod 12.51 with diameter 1.0 and $1.2 \mathrm{~mm}$ was used for these experiments. Both wires were tested by three values of the welding current (140, 200 and $280 \mathrm{~A}$ ), wherein the welding speed ranged 0.2 $0.7 \mathrm{~m} / \mathrm{min}$. How the welding speed influences the size and the shape of the weld pool in case of welding current $280 \mathrm{~A}$ and a wire diameter of $1.2 \mathrm{~mm}$ is shown in Figure 9

For each value of the welding current, six testing samples were made for both wire diameters. Welding took place in the synergic mode, and therefore the different current density, given by the different filler wire diameter, could be considered. The wire feeding

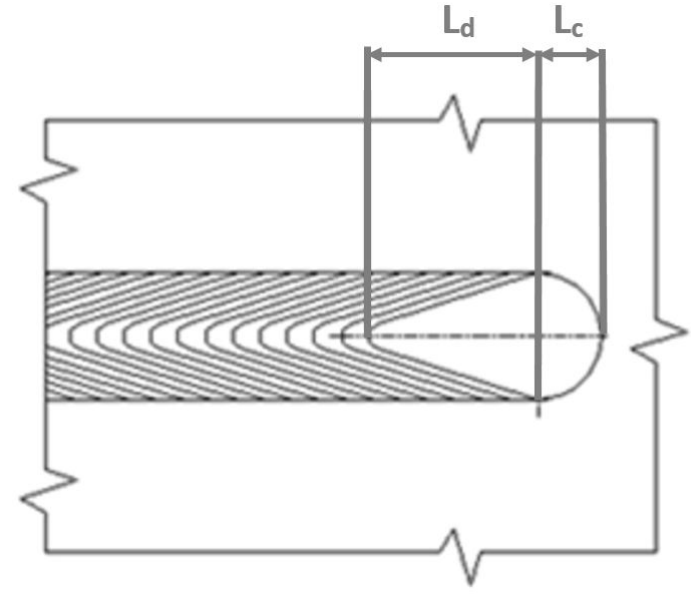

Figure 8. Geometrical parameters of the weld pool.

speed is lower when using a wire of a larger diameter. The value of the heat input per length unit ranged $0.33-1.2 \mathrm{~kJ} / \mathrm{mm}$ for the wire of a $1.2 \mathrm{~mm}$ diameter. In the case of the wire of a $1.0 \mathrm{~mm}$ diameter, the heat input values were approximately $12-21 \%$ higher.

The first monitored geometrical parameter was the size of the fillet weld $a$. Due to the higher current density in the case of the wire diameter of $1.0 \mathrm{~mm}$, the parametric variables increase, when compared to the diameter of $1.2 \mathrm{~mm}$. It is possible to say that the wire diameter of $1.0 \mathrm{~mm}$ enables higher melting at about $10 \%$. This explains why it is possible to achieve higher fillet weld sizes $a$ in the case of using the lower wire diameter, see Figure 10.

From the obtained curves, it can be seen that the deviation of $10 \%$ in the fillet weld size has been achieved only for the current of $200 \mathrm{~A}$. For other current values, there are always smaller deviations. Similar courses and deviations, were achieved for the parameter weld width $w$.

Slightly different is the situation for the depth penetration $v_{\max }$, see Figure 11 For low values of the welding current, there is almost no effect of the wirediameter change. Only with the increasing value of the welding current, this difference begins to be important. At the current of $200 \mathrm{~A}$, the difference in the $v_{\max }$ is already $13 \%$, and at a current of $280 \mathrm{~A}$, even $18 \%$. This progression of increasing the penetration depth can be explained by the change in the flow direction and velocity in the weld pool. The temperature gradient is steeper, which results in achieving a deeper penetration.

The same progression can be seen in the case of the total welded surface $P_{c}$, which shows the same effect of the welding current. The total welded surface is determined mainly by the weld width $w$ and penetration depth $v_{\text {max }}$, which are thus the most important variables. In Figure 12, it is possible to see the effect of the wire diameter rebound already at low welding currents. With the current growth, this effect on the overall size of the weld further increases. 

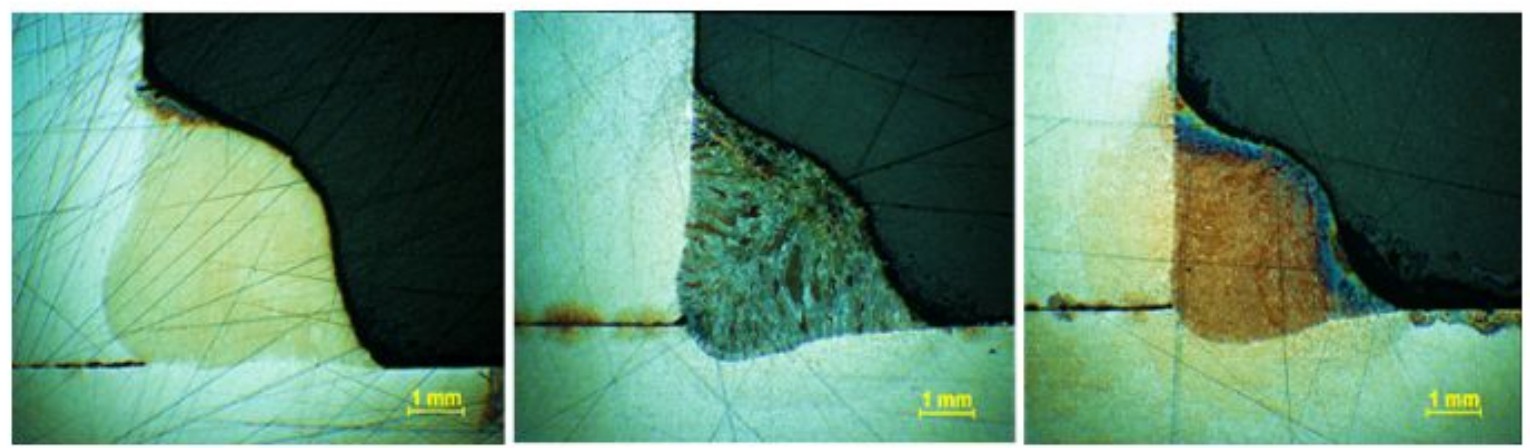

Figure 9. Welded samples at a different welding speed: (a) $0.3 \mathrm{~m} / \mathrm{min}$, (b) $0.4 \mathrm{~m} / \mathrm{min}$, (c) $0.5 \mathrm{~m} / \mathrm{min}$.

Fillet weld size "a" vs. welding speed

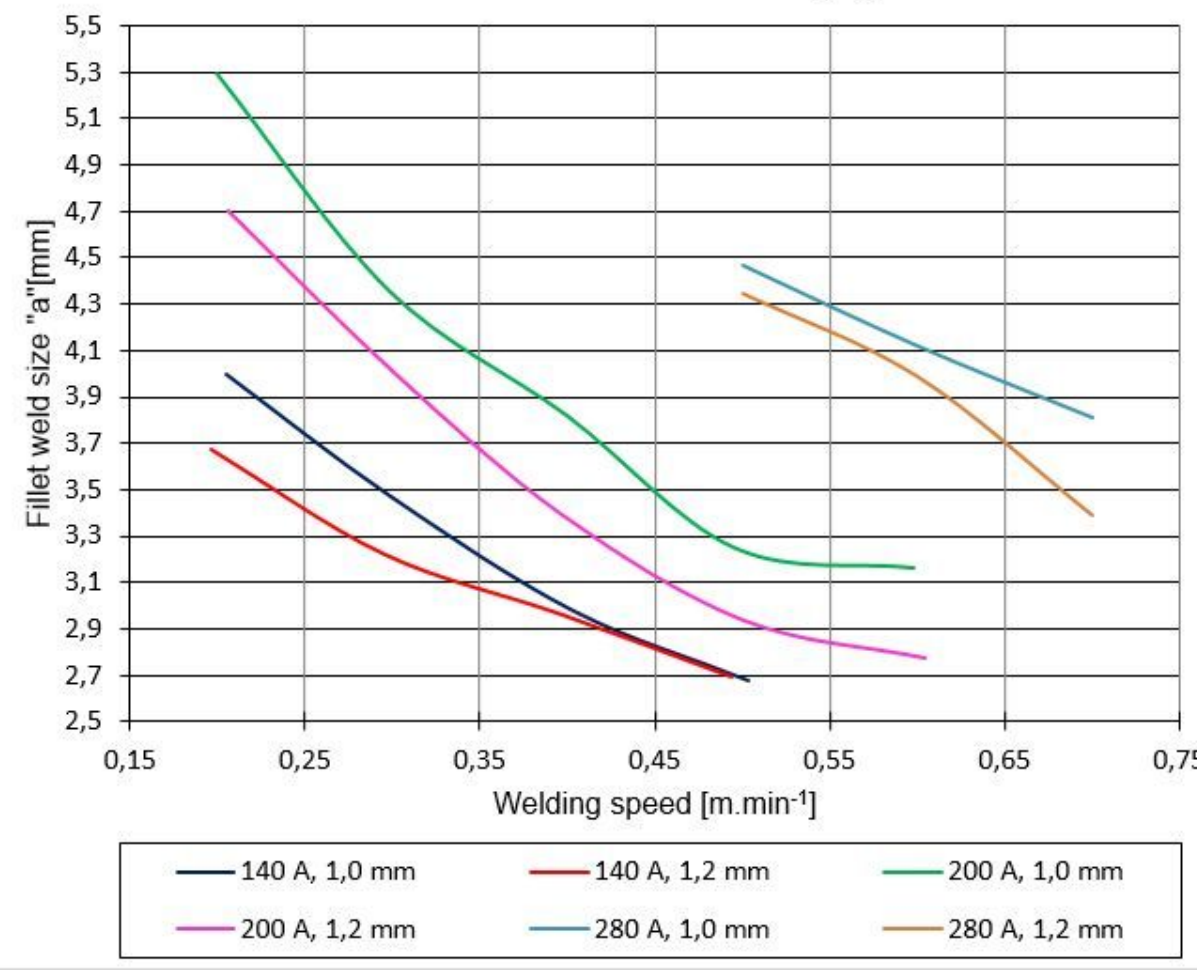

FiguRE 10. Fillet weld size dependence for selected welding currents and wire diameters.

\subsection{EXPERIMENTS BY DIFFERENT PREHEATING TEMPERATURE}

For the material S355J2, there is no need to use preheating in case of smaller material thickness. For numerical simulation, however, the preheating effect and its influence on the weld pool geometry are important. In addition, the thermal conductivity of unalloyed and low-alloyed steels, which require preheating, is comparable to the steel S355J2 and results obtained with this cheaper material, and thus can be applied to these steels. The wire OK Autrod 12.51 with a diameter of $1.2 \mathrm{~mm}$ was used for the experiments. Preheating temperatures were chosen as 100,200 and $300{ }^{\circ} \mathrm{C}$ with welding speed of $0.2-0.5 \mathrm{~m} / \mathrm{min}$ and the welding current of $140 \mathrm{~A}$. Higher welding speeds were not used because of the small amount of filler material melting.
The same geometric parameters were chosen as for the dimensional analysis by different wire diameters.

When evaluating the parameters $a$ and $w$, it can be stated that the preheating has no significant effect on the size of the fillet weld because the differences in the sizes of both parameters were minimal. This can be explained by the constant wire feed speed during each experiment, since both variables are formed by the filler material.

Deviations were observed only for the parameter $v_{\text {max }}$, because the increasing preheating temperature increases the maximum penetration depth. This is valid for the whole speed range of welding speeds, see Figure 13. It is possible to observe that the curves have very similar slopes and at the temperature of $300{ }^{\circ} \mathrm{C}$, the penetration depth is about $25 \%$ higher than for the weld without the preheating. 


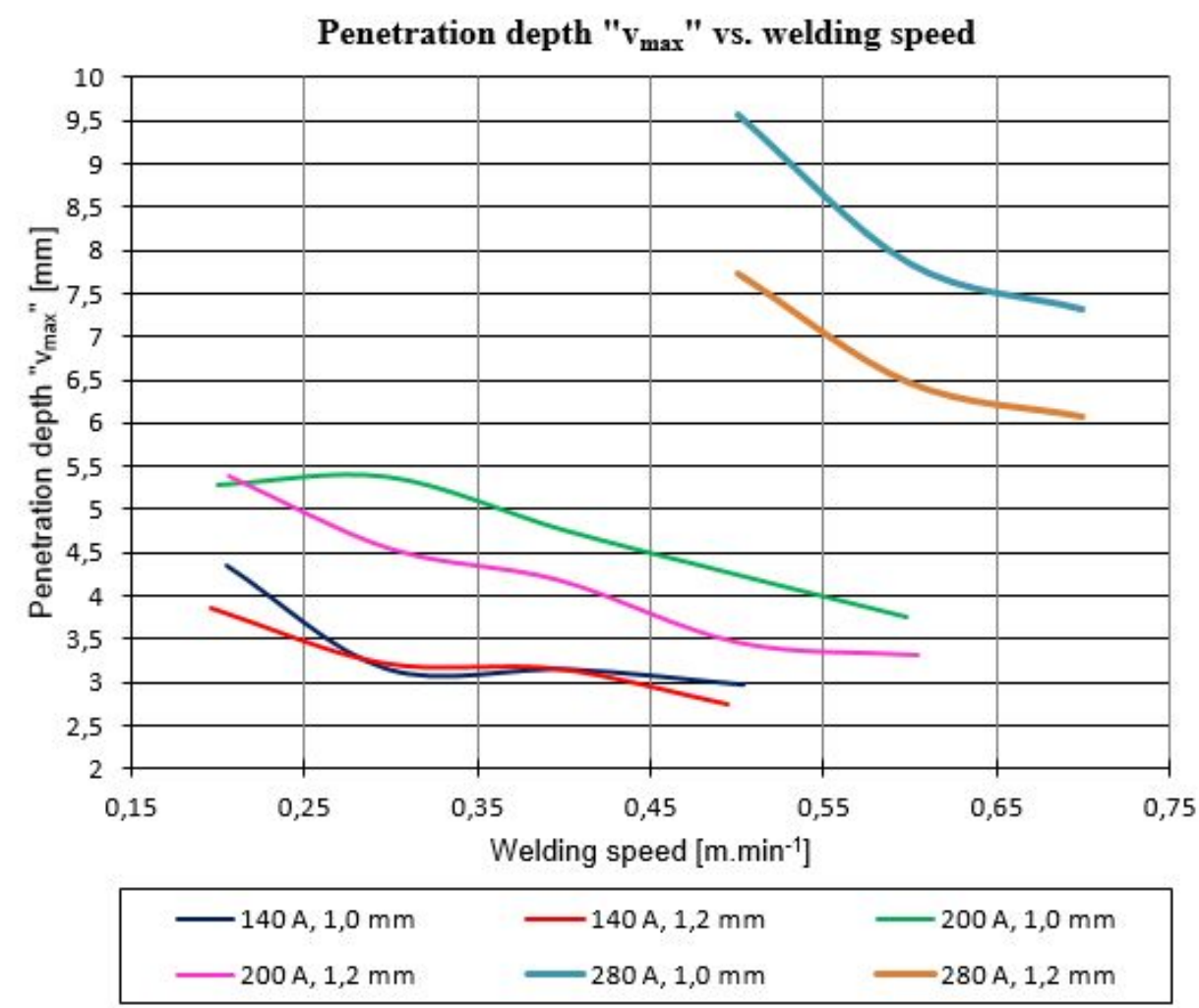

Figure 11. Penetration depth as dependent on welding speed for selected welding currents and wire diameters.

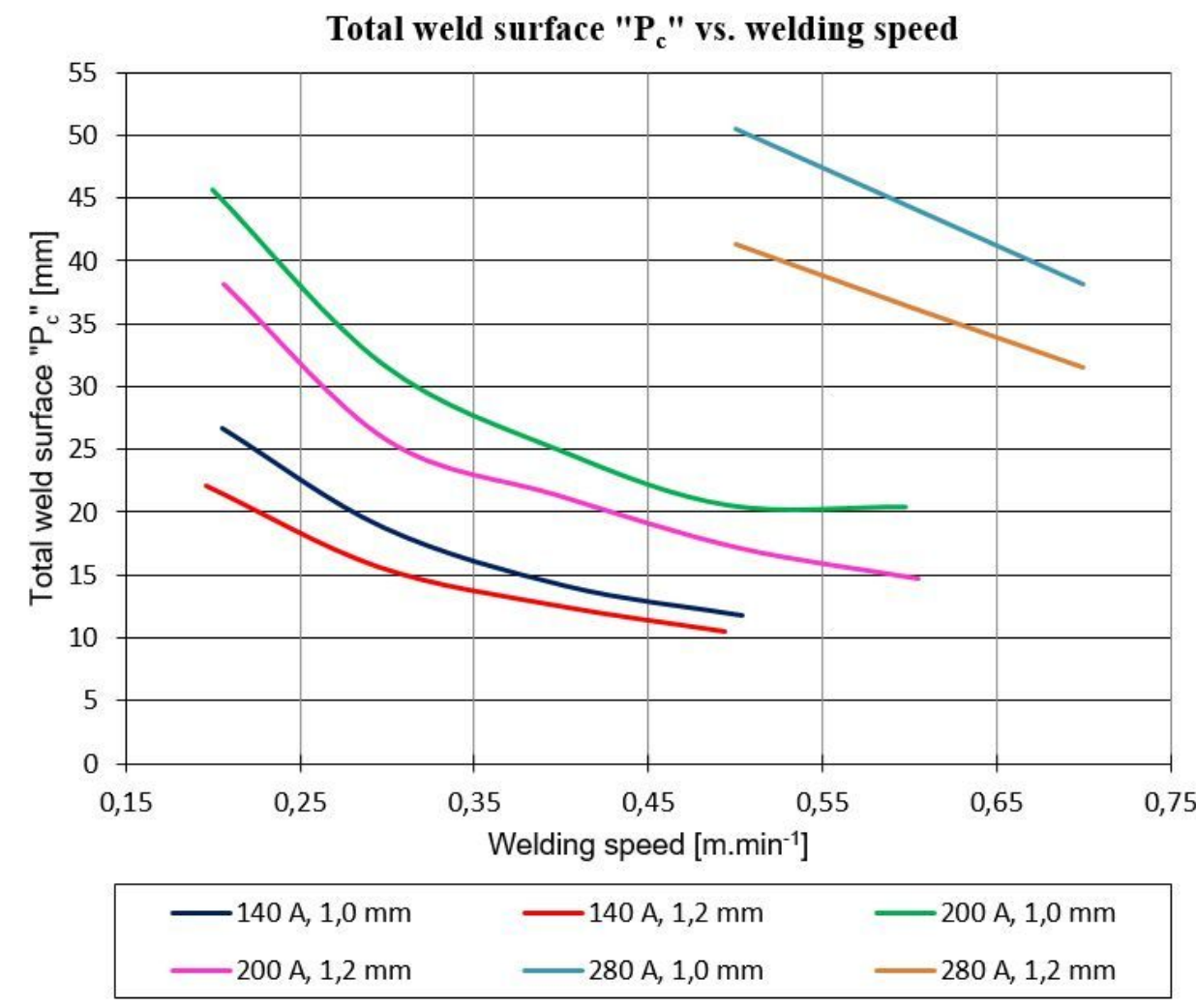

FiguRE 12. Total welded surface dependence on welding speed for selected welding currents and wire diameters. 


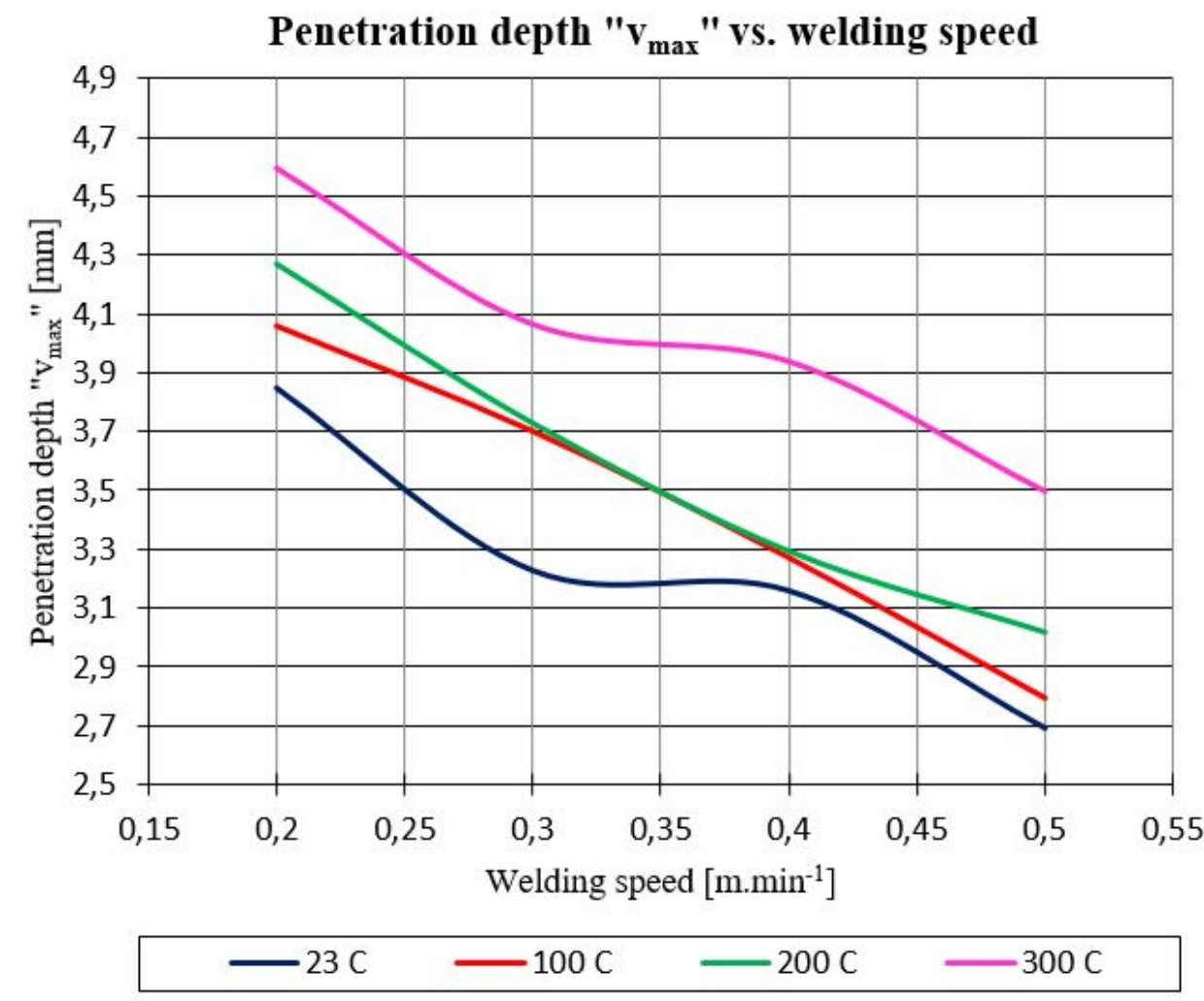

Figure 13. Penetration depth with dependence on welding speed for selected preheating temperatures

\section{UTILIZATION OF THE WELD POOL GEOMETRY FOR OPTIMIZATION OF SIMULATION CALCULATIONS}

The main task of simulation calculations is that the outcome reflects the real state of the simulated action as much as possible. The accuracy of the simulation calculations depends on the quality of the input data. It is not possible for each numerical analysis to realize the experimental determination of the welded geometry. Therefore, it is important to predict geometrical parameters for the defined material and welding method. Then, it is possible to prepare a simulation calculation for a different situation without individual experiments.

As already mentioned in the case of arc welding, the most frequently used model of the heat source is called the double ellipsoidal model, see Figure 14

The double ellipse model of the heat source is described by two equations:

$$
\begin{aligned}
& q(x, y, z)=\frac{6 \sqrt{3} f_{1} Q}{0.5 w v_{\max } L_{c} \pi \sqrt{\pi}} e^{\frac{-k x^{2}}{0.5 w^{2}}} e^{\frac{-l y^{2}}{v_{\max }^{2}}} e^{\frac{-m \xi^{2}}{L_{c}^{2}}} \\
& q(x, y, z)=\frac{6 \sqrt{3} f_{2} Q}{0.5 w v_{\max } L_{d} \pi \sqrt{\pi}} e^{\frac{-k x^{2}}{0.5 w^{2}}} e^{\frac{-l y^{2}}{v_{\max }^{2}}} e^{\frac{-m \xi^{2}}{L_{d}^{2}}}
\end{aligned}
$$

and defined by the heat flux density in the material $q$ $\left[\mathrm{W} / \mathrm{m}^{3}\right]$ separately for each of the ellipsoids. In the equations, $Q[\mathrm{~W}]$ is the total source power given by the voltage and current, $0.5 \mathrm{w}[\mathrm{m}]$ is the parameter of the molten area, which, for fillet weld, defines half of

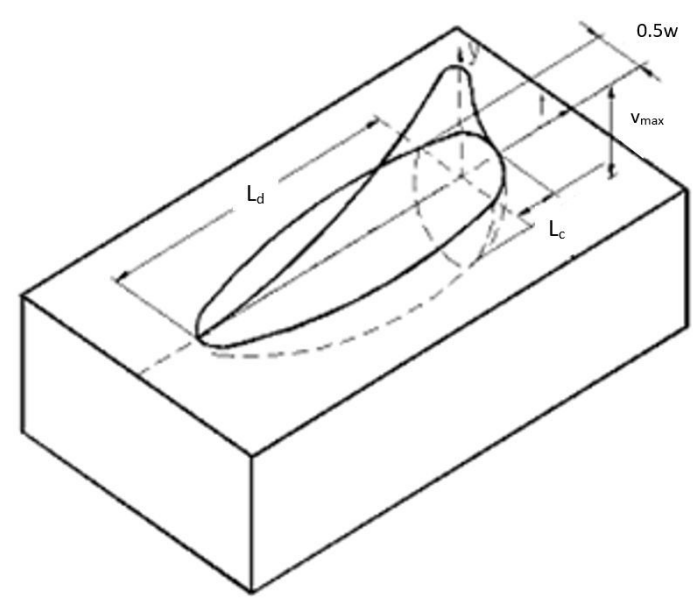

Figure 14. Description of the double ellipsoidal model of the heat source [19].

the weld pool width (Figure 6), vmax [m] defines the penetration depth, Lc and Ld define the geometry of the weld pool in the welding direction (Figure 8), k, l, $\mathrm{m}$ [-] are the coefficients for modifying the shape of the heat source. How much heat, produced by the heat source, goes into front and rear ellipsoid is decided by parameters $f_{1}$ and $f_{2}$. The sum of $f_{1}$ and $f_{2}$ is $100 \%$. The heat power is usually divided: $60 \%$ in the front ellipsoid $f_{1}$ and $40 \%$ in the rear ellipsoid $f_{2}$.

Figure 15 shows the profile of the melting area, which was achieved thanks to the measured geometri- 


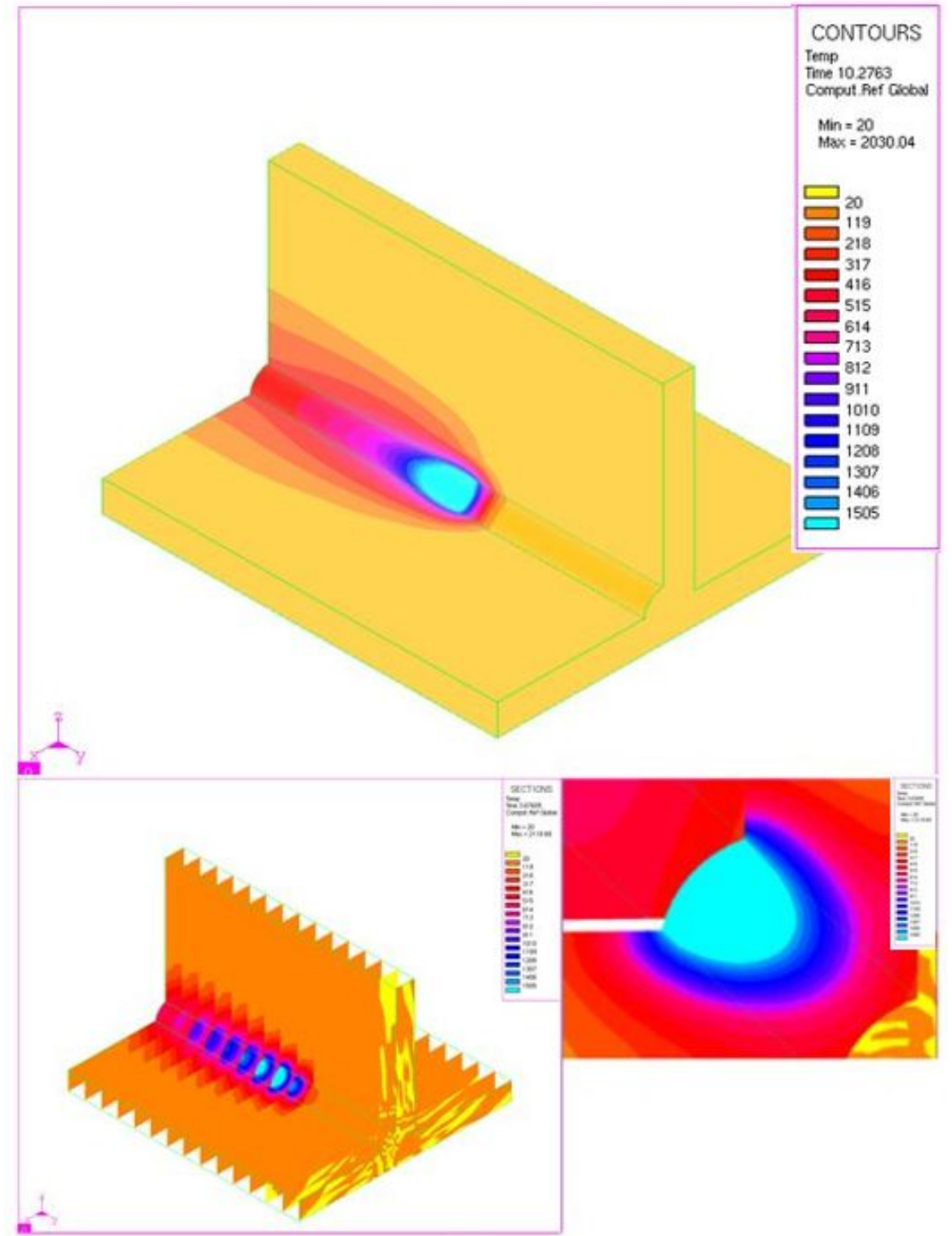

FIGURE 15. Temperature field during welding and detail of the melting area in $x y$ plan.

cal parameters of the weld pool and corresponds to real conditions. If the corresponding values of temperature fields are obtained, it is then possible to calculate the stress and distortion. This calculation cannot be determined without the heat load of the system, which is why optimizing the temperature fields and determining the correct parameters of the weld pool is so important. Without these values, it is not possible to calculate the stress state and distortion.

\section{Conclusion}

Welding is a complex process with many variables, resulting in a certain shape of the weld pool and the temperature gradient. The paper analysed the effect of the various process parameters on the geometry of the weld pool during the arc welding in the shield gas atmosphere.

First, the influence of processing parameters, focusing on the technological parameters, was theoretically described. The particular links between individual parameters were determined. For selected technological parameters, the defined range of process parameters $a, w, v_{\max }$ and $P_{c}$ was determined. This data can be used both for the calculation of operating stress of steel structures and numerical simulations. The results, however, only reflect the system base material (unalloyed or low-alloyed steel) — shielding gas M21 - defined wire diameter (1.0 or $1.2 \mathrm{~mm}$ ). This makes it possible to do numerical computations with sufficient accuracy without geometric verification based on experiments. It is then sufficient to verify only the final simulations' variant, which leads to significant economical and time savings.

Currently, a special software, which will be able to predict the geometric variables based on analytical equation is being prepared. The experiments described in this paper are used among others for the right set-up of this software. The procedure of plan- 
ning and preparing experiments and the methodology to assess their results can be considered as the basis for further and easier description and modification of the heat source model for the arc welding in the shield gas atmosphere.

\section{REFERENCES}

[1] C. R. Heiple, J. R. Roper. Mechanism of Minor Element Effect on GTA fusion zone geometry. Suplement to the Welding Journal, pp. 92-102, 1982.

[2] W. Pitscheneder, T. DebRoy, K. Mundra, R. Ebner. Role of sulfur and processing variables on the temporal evolution of weld pool geometry during mutikilowatt laser beam welding of steel. Welding Journal 75(3) pp. 71-80, 1996.

[3] A. Farzadi, S. Serajzadeh, A.H. Kokabi. Int J Adv Manuf Technol (2008) 38: 258. DOI: 10.1007/s00170-007-1106-9

[4] C. Limmaneevichitr, S. Kou. Experiments to Simulate Effect of Marangoni Convection on Weld Pool Shape, Welding Journal 79(8) pp. 126-135 2000.

[5] L. Quintino, O. Liskevich, L. Vilarinho, et al. Int J Adv Manuf Technol (2013) 68: 2833. DOI:10.1007/s00170-013-4862-8

[6] S. Wang, R. Nates, T. Pasang, et al. Modelling of Gas Tungsten Arc Welding Pool under Marangoni Convection. Universal Journal of Mechanical Engineering. 3(5) pp. 185-201, 2015. DOI: 10.13189/ujme.2015.030504

[7] J.I. Achebo. Complex Behavior of Forces Influencing Molten Weld Metal Flow based on Static Force Balance Theory. Physics Procedia. 2005(12). pp. 317-324. DOI: 10.1016/j.phpro.2012.03.090

[8] P.A.A. Khan, T. Debroy T., S.A. David. Laser Beam Welding of High-Manganese Stainless SteelsExamination of Alloying Element Loss and Microstructural Changes. Welding Journal. 1988 (67). pp 1-7.
[9] A. De, T. DebRoy. Probing unknown welding parameters from convective heat transfer calculation and multivariate optimization, Journal of PhysicsApplied Physics, 37, pp. 140-150, 2004. http://dx.doi.org/10.1088/0022-3727/37/1/023

[10] T.A. Palmer, T. Debroy. Numerical modeling of enhanced nitrogen dissolution during gas tungsten Arc welding Metall and Materi Trans B. 2000(6).pp 1371-1385. DOI:10.1007/s11663-000-0023-1

[11] P. Sahoo, M. M. Collur, T. DebRoy. Metall. Trans. B, 1988, 19B, pp.. 967-972.

[12] M. Takahashi1, H. K. D. H. Bhadeshia. A Model for the Microstructure of Some Advanced Bainitic Steels. Materials Transactions, JIM ,Vol. 32 (1991) pp. 689-696. DOI: $10.2320 /$ matertrans1989.32.689

[13] D.Y. Li, Szpunar, J.A. A Monte-Carlo simulation of the electrodeposition proces. JEM (1993)22: 653. DOI:10.1007/BF02666412

[14] Welding Metallurgy, American Welding Society, 4th ed. 1994.

[15] R. Kopriva. Technology of MIG/MAG welding. 1. ed. Ostrava: Zeross, 1993. 194 p. ISBN 80-85771-004-4.

[16] V. Pilous. Meterials and their behaviuor during welding. Zeross, Ostrava 2001, 292 p.

[17] V. Ochodek. The effect of temperature welding mode on weld mechanical properties. Technical university of Ostrava, 2011.

[18] O. Ambroz. Welding technology. 1. ed. Ostrava: Zeross, 2001. ISBN 80-85771-81-0.

[19] J. Moravec, J. Sobotka., J. Bradac. Numerical Simulations Utilization for Welding Hardly Weldable Materials Based on Iron Aluminide. Liberec 2010. 98 p. ISBN 978-80-7372-682-9. 